\title{
The Fear of Camp Life: Understand the Spatial Reality and Formation of Discourse
}

\author{
Joydip Dutta
}

PhD Scholar, Tata Institute of Social Sciences, Mumbai, India, E-mail: joydipdaju@gmail.com

\begin{abstract}
The paper makes an existentialist analysis of refugee Camps in West Bengal that came into being after the Indian Partition in 1947 when the state received a large number of asylum seekers from the-then East Pakistan. The objective of the paper is to discuss the construction of Camp life in terms of the affect of fear. Camps have been largely interpreted as the active agents of rehabilitation, space of political movements or supplier of informal labourers. The principal enquiry here however would be to interrogate if the camp is home for the refugees or it has a separate existential reality in the face of fear which goes beyond the questions of rehabilitation. Borrowed from Martin Heidegger's Being and Time (1927) the concept of fear in this paper does not indicate any specific character or definite future. Rather, fear unfolds as an 'affect'. In West Bengal, construction of the Camp by the government was presupposed for rehabilitation of the refugees from East Pakistan (Bangladesh). Hence, in-itself a Refugee Camp functioned to control the population by its norms, rules, and regulations. On the other hand, it was constructed as temporary shelter for the refugees. Therefore, the temporal character signifies how Camp constitutes the refugees through 'care' and how they encounter reality in that situational condition. The paper will not focus on fear as only as detrimental to the life of the refugees. Rather, it tries to show how the affect of fear may also unfold the possibility of that space by engaging with the elements of speech, silence or listening that constitutes the discourse of Camp. The paper would explore how as a temporary shelter of the refugees, Camp life has been constructed as a discourse in terms of spatial boundary and limits. Coopers Camp in Ranaghat, West Bengal here is taken as a case study to explicate the discourse of camp life in the light of fear and ontologically address the refugee question in post-Partition subcontinent.
\end{abstract}

Keywords: Refugee Camp, Fear, Affect, Space, Rehabilitation, Experience

This paper will try to discuss Coopers Camp one of the significant temporary refugee settlements in West Bengal set up by the government to house the homeless migrants from East Pakistan after the partition of India. The discourse of refugee studies in academia generally focuses on the question of national border, citizenship, identity and the governmental act of rehabilitation of the displaced population. This paper however would attempt to locate the relationship of fear as an affect within the space of the Camp and try to show how it shapes the Being of the Camp. This tries to induce an existential reading of the Camp space and its being as such without assuming the refugee identity as a governmental or historical category that is pre-given. It is more an experiential category in the present reading. Departing from interpretations which focus on the process of rehabilitation of the refugees and their condition of homelessness, here Camp shall be interpreted as an existential reality mediated by fear. The refugee crisis is largely considered as

(C) AesthetixMS 2020. This Open Access article is published under a Creative Commons Attribution Non-Commercial 4.o International License (http://creativecommons.org/licenses/by-nc/4.o/), which permits non-commercial re-use, distribution, and reproduction in any medium, provided the original work is properly cited. For citation use the DOI. For commercial re-use, please contact editor@rupkatha.com. 
the result of a mass phenomenon and often interpreted either as threat to the host society or seen in terms of humanitarian ground of obligation for the state to resettle them and provide with means of livelihood. On the other hand, the appearance of the refugees is considered as a temporary condition between naturalization and repatriation that acquired a decidedly disquieting element and unhinges the old trinity of state/nation/territory. As a result of this existence, the category of refugee looks like a marginal figure. In this context we can bring in Agamben's suggestions to read and articulate Camp as a conception deviated from the general rights of man. (Agamben 1995, p. 115) This conception in Agamben in a paradoxical condition is a model of new international relation (Agamben 1995, p.115). As the subject of history, the 'refugee' crisis gets explicated in terms of understanding the origins of the population of displacement and making sense of their way of displacement (Gatrell 2013, p.12). Hence, the historical event correspond the cause of its origin in which the question of refugee becomes a subject of history, politics, and international relations and scholars are supposed to find out the way to dissolute the subject as threat. ${ }^{1}$ The meaning of the Camp in this inquiry could be read as an agent of the process of rehabilitation and investigates how it functions for rehabilitation of the refugees. Here the role of the Camp is substantiated in terms of assistance of the relief work. Anthropological intervention articulates the question refugee as an epistemic object in terms of its experience, and culture and is read as an interdisciplinary subject of inquiry (Malkki 1995, p.515). The cultural context directs the investigation in terms of spatiality because the distinctness between the place and space is interpreted by culture and becoming refugee is 'out of the place' (Brun 2001, p.18). Therefore, existence of the refugees, uprooted from one place to another, is considered as the result of a loss of culture. In this sense, through a process of naturalization, the population is meant to get absorbed in the culture and habits of the new place (Brun 2001, p.18).

In the general interpretation of refugee studies the Camp is explicated as a space of embodied practice which constructs a new community within a new area (Brun 2001, p.19). Therefore, in-itself the Camp is projected as reterritorializing the refugees by expanding the network and culture of practice and making itself suitable for daily life of them. As spatial arrangement, meaning of the Camp is described as a society that becomes a space of discipline and agency in which it comported its territory with displaced population. After the Second World War, the refugee Camps signified spatial concentration of standardized, generalizable technologies of power and ordering of people (Malkki 1995, p. 498). The idea of space in Camp has been considered as physical belonging and it explicated how physically it functioned for the rehabilitation of the refugees. It has been also argued that the refugee Camp is a space of hospitality or it acts as social, cultural and political space for assemblage of the refugees for restoring their permanent political life as citizens (Ramadam 2012, p.74). In another manner, spatial consideration has disclosed the temporal structure of the Camp and it is articulated as the space of displacement referring to time of dislocation of the refugees (Ramadam 2012, p.73). The common feature of the refugee Camp has its temporal character and the meaning of temporality is interpreted with a focus on how physically the refugees took temporal shelter as opposite to home. In this sense, human geography or anthropological elucidation of temporality has largely considered the Camp as a space of the displaced people with reference to its physical structure. It is like a new community, a new area and a time of interruption from their earlier life. Other than this, the temporal arrangement of the Camp produces a kind of society that has been looked at from a humanitarian perspective. Beyond this articulation, the existence of the Camp is projected as a historical object which has its past, present and future and is marked by the transition of the human being within a society (Mortland 1987, p.375). Giorgio Agamben's reading of camp as a state of exception has also appeared to be in continuation with the geographical apprehension of 
the Camp and this interpretation is largely directed towards regarding it as a spatial category. The paper is quite far from considering the Camp as physical category; rather here the departure from Agamben's methodological articulation of the Camp is in reading it as a Being and here an investigation of the Camp's functional character with regard to ontology shall be attempted (Agamben 2009, p.32).

The refugee question in subcontinent is deeply connected with the event of Partition in 1947, because the crisis of refugee influx appeared after creation of the two Nation states of India and Pakistan. Discourse on Partition and the question of refugee lies in two different types of social configuration in the East and West of India. ${ }^{2}$ As subject, the refugee is interpreted in literature in terms of the creation of the two new nation states and the communal violence that nourished the process of refugee-making. Therefore, to understand 'the question of refugee' here on one side is 'binding something', that is the creation of an international border and its respective socio-political scenario, and on the other side, violence has been an important tool to articulate the facts of migration (Butalia 1998). The rehabilitation of the refugees, role of the state, becoming the citizen of new state, self-initiative for arrangement of the rehabilitation, and spatial dimension of the new settlement like refugee Colony and Camp also became the subjects of inquiry. However, the general trend is to consider the existence of refugee as a historical subject and make sense of the way the refugees are included within the state and the respective role of the state (Chatterji 2007). Hence, interpretation of the Camp is largely articulated through the historical event of the Partition and the Camp has been looked at in terms of the refugee rehabilitation. The paper here however studies a single Camp not in terms of its being the subject of history but rather to show how its meaning gets unfolded in the discourse through narratives of experiences of the Camp inmates.

The 'Manual of Instruction for the Guidance of Officers of the Refugee Relief and Rehabilitation Department' (1954) was the instruction and guideline for the refugee rehabilitation directorate and it mentioned the way rehabilitation would be carried forward. Most significant section of the manual has referred the details of administrative structure and specific functional character of camps in Bengal. The structure or organization of the camps has been perceived according to the influx of the refugees after partition of India (1947) and the categorization generally comprised of three types. They are the Transit/ Relief Camps, the Work-site Camps, and the Colony Camps. Beside these three categories, there were Permanent Liability Institute (popularly known as P. L. Camp) and Women's Camp, which were controlled separately (Manual Refugee Relief and Rehabilitaton 1954, p.13). However, these three types of categorization were determined by the occupation of the able bodies for work from the refugee families. This paper is focusing on a single refugee Camp named Coopers, which is located in Ranaghat, West Bengal as an example to understand the way it functions and the way life can construct a discourse within the spatio-temporal arrangement. However, there is a common trait between these three categories of Camp, and it can be marked by the temporal belonging of the refugees. In this sense, transit Camp evokes such common trait very prominently, because its basic foundational character was premised upon temporary shelter of the refugee families. The construction of the Coopers was very purposive for immediate assistance given to the people whose life was disrupted by the sudden event of partition. Basic organizational pattern of the Coopers was controlled by the Government of India, but on $2^{\text {nd }}$ July 1951 the camp was handed over to the West Bengal State Government (Basu 2017, p.168). The opening date of the Camp was March, 1950 and the area was nearly two and half squire miles (Committee of Review of Rehabilitation Work in West Bengal 1969, p.143). Initially the population of the Camp was over one lakh and therefore, internally the whole area was divided into five blocks and each block had a supervisor and a guard for 
maintaining the rules and regulations (Roy 2011, p.154). Before becoming a refugee Camp, the Coopers was a military artillery barrack. Hence the place was constructed for the military purpose during the Second World War and after Partition it was transformed into a temporary shelter for the refugees. The early construction provides some positive clue for arrangement of the place and methods of control of the refugees, as primarily the place was made to restrict movements within and outside its limits.

In the general interpretation of the refugee Camp in sociological, anthropological or humanitarian perspective, it is projected as a place of identity, hospitality, resistance or politics. Therefore, it is projected as the physical place that either would include the refugees into the mainstream process of nation state building or would repatriate them in their original place. As refugee Camp, the Coopers Camp was primarily constructed for managing the refugee population and to permanently rehabilitate them. The general phenomena of the Camp can articulate two aspects - firstly, how the administration controlled the refugees by rules, norms and regulation. Secondly, it shows how experience of the refugees explicates their life and unfolds the way they exist in the Camp. The paper does not consider the above categorical interpretations of the Camp; rather, it focuses on a single entity to show how it functioned and more specifically how the phenomena of the fear constitutes the Being of such a place. It does not mean that the paper proposes fear as categorical to understand the refugee Camp being fearful than other places. But fear can unfold the language in that temporal situation. The concept of fear has been borrowed here from Martin Heidegger's seminal work Being and Time (1927) for the purpose of the analysis of temporality and the meaning of the Being with respect to time. For him fear has some specific character in which the being fears in the face of something threatening and therefore fear signifies the everyday circumspection and refers 'in time' when the threat of the fear 'affect' the Being (Heidegger 1962, p.391). However, the phenomena of 'fear' as subject do not indicate any specific character or definite future. Rather the fear lies in the character of 'affect'. Heidegger's interpretation of fear is a state of mind and it appears from the lost present of the Being (Martin Heidegger 1962, p.395). In the face of fear, he articulates ec-static (as going beyond the static and towards an outside of decidability) temporality of understanding the meaning of the Being i.e., making sense of the Being from within the temporality but at the same time having the potential to go beyond. In this sense fear indicates a state of mind in which meaning of the basic existence of Being can unfold. In other words, it questions history in terms of the present and thinks about the present through the process of designating future possibility. Heidegger would maintain in a hermeneutical manner that the phenomenal possibility of the unity in future does include the Being conceived in a particular temporal existence. Hence fear suggests the ontology in which Being can be interpreted by its expression of speaking and listening otherwise than a stable, pregiven existence. The language and discourse of fear makes it possible to address the phenomena of the future unity.

As refugee Camp the Coopers appear through the sudden event of Partition and exigency of influx of the refugees from the East Pakistan to West Bengal. It has already been mentioned that the Camp has kinds of rules, norms, and regulations by which it controls its inmates. Therefore, in-itself refugee life has passed through such environment. Primarily as members of the Camp inmates, the administration provided rehabilitation assistance which is popularly known as dole. It was of two types. The dry dole mainly covered rice, wheat, and sesame, and cash dole consisted of a very nominal amount of money for purchasing other materials. The significant part of the rehabilitation assistance on one hand is a tool to control the refugees, because primarily without rehabilitation assistance it is difficult for individuals to exist in the Camp. On the other hand, dole tried to produce a kind of body inside the Camp, where as refugee one is not 
allowed to do any kind of work outside that designated space (Roy 2011, p.161). Primarily, there is restriction of the individual for movement beyond their allocated place. Dole remained permanent for expenses of the everyday life and was a part of the environment of the warehouse where refugees were initially arranged to stay (Gauranga Das, Personal Communication, June 18, 2007). As a result everyday phenomena of the Camp created a kind of lassitude among the refugees. However, the general phenomena consisted of overcrowdedness and lack of hygiene. Spread of infectious diseases like cholera, chickenpox, and typhoid was common, and death was familiar in the Camp life (Singha 1999, p. 26). The paper suggests that through this environmental condition and by the norms of the administration, in-itself the Camp produced a kind of fear within its boundaries. General pattern of the Camp had followed certain norms and therefore as being a refugee should obey it. But if some action of the refugees crossed the general rules and norms, immediately the administration punished them by cutting off the name from the dole list. The experiences of the refugees explicated how initially if anyone moved out of their allocated place and got noticed by the guard, it would be a punishable offence. On the other hand, the location of the Camp was surrounded by a jungle and sometimes wild ferocious animals attacked the inmates and death was a common phenomenal experience. Narratives of the inmates described the burning place where tinder has been issued for funeral and in every single day more than a hundred bodies used to burn. The basic functional character of the transit Camp was temporary shelter for the refugees and therefore refugees had no definite possibility in the space for staying permanently in future. In this sense, existence in Coopers was mediated by the conditions of fear, anxiety, suddenness, and ambiguity of the refugee life which may unfold through the discourse on camp life, as gathered from the oral narratives and interviews of the people who inhabited the space.

Darkness is another important element in these narratives that has been effective in symbolizing Camp life and constituting the affect of fear. The space of the camp has been dark due to absence of light at night, but beyond that physical darkness the image of that space carried a sense of fear characteristic of the environment of the camp space. We can find such descriptions either in the narrative of camp inmates or literary works based on the environment of the Camp. The image of darkness is prominent there. The night in the Camp has not only been characterized by darkness but rather by the fear of death. Tushar Singha in his engagement with refugee politics in his experiential novel Maranjoyee Sangrame Bastuhara (1999) (The Refugees and Their Struggle Against Death) has mentioned about the insufficient arrangement of lights inside the camp and according to him due to inadequate arrangement of light the whole area of the Camp was wrapped in a kind of silence (Singha 1999, p.26). We have already discussed how the location of the Camp was surrounded by a jungle and wild ferocious animals attacked the inmates and death was phenomenally common (Roy 2011, p.155). In Cooper's Camp Monoranjan Das used to stay in forty-two number 'Nishenhaat' with his wife and his five years old daughter Manjubala. His daughter slept beside her parents. One day suddenly at one o'clock at night a scream awoke him and his neighbours and they discovered that the daughter was not in the room. They followed the scream of her daughter and finally identified that an animal was taking her over and disappeared in the jungle. Next day they found the dead body of their daughter (Bandyopadhyay 1970, p168.). This kind of fear was detrimental in terms of its effect on the life of the Camp and there was something queer about the existence of the refugees in such a condition. The narrative unfolds the phenomena of darkness and explicated how it produces a condition of perpetual fear for the inmates staying within that space.

The meaning of the Camp unfolded a kind of fear. In other words refugees faced a form of threat which is ruinous for their present existence. It appears through the everyday circumstances 
and is connected with their future rehabilitation. Being threatened either by the environment or rules of the Camp in a certain way challenge the potentiality of the refugees. Phenomena of death, diseases, or other threats 'affect' the life of the refugees and force them to think about their present condition through a temperament of threat. The rules or conditions of the Camp did not allow any language which can oppose or question the limitations of the rehabilitation arrangements. Hence possibility of future in the life of the refugees primarily lies in encountering or questioning the function or future of the Camp. However, the refugees primordially had no such experience earlier and the new environment and specific character of fear leads them to be concerned of their life. Therefore, unity was formed in the face of awaiting threat either to protect them from the attacks of the wild animals or encountering the limited arrangement of relief in Camp. Ratish Basu Mallick, who was the founder of the Coopers Camp Bastuhara Committee, initially started questioning the low quality of food provided by the administrators. ${ }^{3}$ Immediately, the administration of the Camp discontinued his regular rehabilitation assistance (dole) as punishment for violating the rules. But it produced the language of the other inmates to articulate and speak about the awaiting threat in their lives. In this sense threat creates the possibility of the refugees to become united and speak against the norms of the Camp and it may unfold their potentiality.

The paper does not propose simply that fear or threat makes the phenomenon of unity. Rather, 'affect' of the threat created the possible ground for the individual to speak and construct the discourse that eventually may produce the phenomenon of unity in this situational condition. For example Ratish Basu Mallick was concerned that life may suffer from a disease as well as the 'affect' of low quality of food supplied for daily rehabilitation assistance and he spoke against the immediate threat of the life in the Camp (Mallick, 1983). The language of his concern about the life and the 'affect' of threat made the possible ground to communicate with other inmates to speak and encounter the functioning character of the Camp. On the other side, as temporary shelter of the refugees the basic character of the Coopers camp was to keep the refugees for a few weeks in that space till the Camp authority arranged a place either in West Bengal or outside for permanent rehabilitation. Hence the refugees faced the fear of temporary stay in the Camp and being displaced again towards an unknown future. However, the 'affect' of the threat makes them understand their present condition in terms of their relationship to the space. The process of speaking against the common threat and the language addressing the environment in which the spatial unity was constructed explicates the distinctness of the existence, or discourse of the Camp refugees in West Bengal.

The paper tried to interpret the existence of the refugee in a particular kind of spatial situation and explicate the ways in which the refugee speaks and a discourse is formed within a temporary state of existence. We already mentioned about the scholarly engagement of the refugee Camps but the paper tried to unfold Heidegger's conceptualization of fear in terms of interpretation of temporality of the Being (Heidegger 1962, p.391). And we explicated Camp as a temporary shelter of the refugees where fear can make a possible ground to understand the present existential condition and the functionality of the Camp. Fear produced the concern for the coming threat in their life within the Camp and it also opens the possibility to encounter and question the rehabilitation process. Hence, fear creates a different form of attachment between the space and the refugees because of the temporary character of the shelter. In this sense, the camp was not their home or it can be said that they did not have definite possibility to think of their existence in the Camp as permanent. Therefore, encountering with the rules and norms of the Camp the refugees asserted and articulated their presence within the Camp space by their own language and they communicated among themselves through speaking about the threat of 
their life. In this way they produced their own discourse of camp life departing from the governmental discourse of displacement and rehabilitation. The empirical reality of the Camp unfolded through arrangement of space and discourse of the refugee population within it refers how the unity of the refugees was formed through the continued presence of a sense of threat and it corresponded to their spatio-temporal existence. Hence, the unity of the Camp refugee or their activism followed a specific pattern distinct from the general refugee movement in West Bengal (Chakrabarti 1990, p. 186) often dominated by inhabitants of refugee Colonies which did not face the threat of further displacement or sense of fear as the Camp space. The paper tried to explicate the distinctness embedded in the language of the refugees and tries to show how it has been formed through the state of fear as a part of the environment of the Camp.

\section{Notes:}

${ }^{1}$ In the general interpretations the question of refugee largely follows two directions. Firstly, the scholars are trying to understand the cause of migration of the formation of refugees and secondly, they are trying to find out the way to solve the refugee crisis.

${ }^{2}$ In subcontinent the Partition refugees generally can be divided in terms of two different geographical locations. The Western part of India where communal violence has been claimed to be more prominent than the Eastern Part, and the Eastern part of India where the influx of the refugees is consider as a continuous process.

${ }^{3}$ The Coopers Camp Bastuhara Samity was the refugee organization specifically in Coopers and it was affiliated to the United Central Refugee Council. Primarily norms of the Camp were against the formation of any kind of organization but the C.C.B.S indicates a kind of unity among the refugees which is largely constituted by the unity of their language of suffering and collective fear.

\section{References:}

Agamben, G. (1995). We Refugee, Giorgio Symposium, Summer.

Agamben, G. (2009). The Signature of all Things: On Method, trans. Luca D'lsanto and Kevin Attell, New York: Zone Books.

Bandyopadhyay, H. (1970). Udbastu, Kolkata: Deep Prokashon.

Basu, A. (2017) ed., Udbastu Andolon O Punarbasati: Samasamayik Patra-Potrikay, Kolkata: Gangchil.

Brun, C. (2001).Reterritorializing the Relationship Between People and Place in Refugee Studies, Geografiska Annaler Series B (1): Human Geography.

Chakrabarti, K. P (1960). The Marginal Men, Calcutta: Lumiere Book.

Chatterji. J. (2007), The Spoils of Partition: Bengal and India (1947-1967), UK: Cambridge University Press.

Committee of Review of Rehabilitation work in West Bengal. (1969). Report on Rehabilitation of Displaced Persons from East Pakistan at ex-camp sites in West Bengal, New Delhi: Ministry of Labour. Employment \& Rehabilitation.

Gatrell. P. (2013). The Making of the Modern Refugee, UK: Oxford University Press.

Malkki. H. Liisa (1995). From "Refugee Studies" to the National Order of Things, Annual Review of Anthropology, Vol. 24, http://www.jstor.org/stable/2155947.

Mallick. R. B. (1983). Interview with Prafulla Kumar Chakrabarti, https://search.socialhestory.org/record.COLLOO190,1983. 
Manual of Instructions for the Guidance of Officers of the Refugee Relief and Rehabilitation Department. (1954). New Delhi: The Refugee Relief and Rehabilitation Department.

Martin. H. (1962). Being and Time, trans. John Macquarrie and Edward Robinson, London: Harper perennial Modern thought.

Mortland. A. C. (1987). Transforming Refugees in Refugee Camps, Vol. 16, No. 3/4, Southeast Asian Refugee in the United States (Fall - Winter, 1987),USA: Urban

Anthropology and Studies of Culture System and World Economic Development, http://www.jstor.org/stable/40553111.

Ramadan. A. (2012).Spatialising the Refugee Camp, UK: Royal Geographical Society.

Singha. T. (1999). Maranjoyee Sangrame Bastuhara, Kolkata: Dasgupta Publications. 